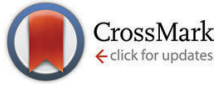

Cite this: Chem. Commun., 2015, 51,4858

Received 7th January 2015,

Accepted 9th February 2015

DOI: $10.1039 / \mathrm{c} 5 \mathrm{cc} 00121 \mathrm{~h}$

www.rsc.org/chemcomm

\section{Surface-immobilised micelles via cucurbit[8]uril-rotaxanes for solvent-induced burst release $\uparrow$}

\author{
Chi Hu, ${ }^{a}$ Yu Zheng, ${ }^{a}$ Ziyi $\mathrm{Yu}^{\mathrm{b}}{ }^{\mathrm{C}}$ Chris Abell ${ }^{\mathrm{b}}$ and Oren A. Scherman ${ }^{* a}$
}

\begin{abstract}
The fabrication, characterisation and controlled burst release of naphthol-functionalised micellar (NFM) nanostructures, which were grafted onto gold surfaces through cucurbit[8]uril (CB[8]) mediated host-guest interactions are described. NFMs undergo a facile change in morphology from micelles to diblock copolymers in direct response to exposure to organic solvents, including tetrahydrofuran (THF), toluene and chloroform. This induced transition in conformation lends itself to potential applications including nanocarriers for triggered burst-release of guest molecules. Nile Red was investigated as a NFM encapsulated model hydrophobic cargo inside the surface-attached micelles, which could be fully released upon exposure to THF as measured by both atomic force microscopy and UV/vis spectroscopy.
\end{abstract}

Controlled immobilisation of stimuli-responsive micelles on solid surfaces has emerged as a vital field for the advancement of surface engineering. ${ }^{1-6}$ This is motivated by the potential applications of such micelles as nanocarriers for the triggered release of guest molecules, which offers the ability to remotely control release with both temporal and spatial selectivity. ${ }^{7,8}$ The hydrophobic nature of the micelle core enables the incorporation of small, uncharged hydrophobic guest molecules as cargo, a desirable feature that has proven to be a challenge using other surface engineering methods such as layer-by-layer (LbL) assembly. ${ }^{9,10}$ While smart micelles responsive to external changes in $\mathrm{pH},{ }^{11-14}$ temperature ${ }^{15,16}$ and light ${ }^{17,18}$ have been reported, to the best of our knowledge, no study has focused on cargo release triggered by changes in solvent.

Increasing interest exists in exploiting supramolecular chemistry to modify surface properties of solid substrates. ${ }^{19-25}$ Cucurbit $[8]$ uril $(\mathrm{CB}[8])$ is a larger member of the cucurbit $[n]$ uril family of macrocyclic host molecules, which is able to encapsulate

\footnotetext{
${ }^{a}$ Melville Laboratory for Polymer Synthesis, Department of Chemistry, University of Cambridge, Lensfield Road, Cambridge CB2 1EW, UK. E-mail: oas23@cam.ac.uk; Fax: +44 (0)1223 334866; Tel: +44 (0)1223 331508

${ }^{b}$ Department of Chemistry, University of Cambridge, Lensfield Road, Cambridge CB2 1EW, UK

$\dagger$ Electronic supplementary information (ESI) available. See DOI: 10.1039/ c5cc00121h
}

one electron-poor first guest (e.g., viologen, $\mathrm{MV}^{2+}$ ) and one electron-rich second guest (e.g., naphthol, Np) simultaneously in its cavity. ${ }^{26-29}$ The successful preparation of $\mathrm{CB}[8]$-based rotaxane sensors on a gold surface was recently reported by our group. ${ }^{30}$ In this stepwise approach, the substrate was firstly functionalised with an amine-terminated self-assembled monolayer, which further reacted with terephthalaldehyde to obtain an aldehyde-functionalised surface. Finally, the binary complex of bis-aminoethyl viologen and $\mathrm{CB}[8]$ was attached to the surface in a rotaxane manner through the coupling reaction between the amino groups and aldehyde derivatives on the surface. Here we report the immobilisation of micelles onto surfaces achieved in a bottom-up fashion where $\mathrm{CB}[8]$-rotaxanefunctionalised gold surfaces are used to capture naphtholfunctionalised micelles (NFMs) via heteroternary complex formation as illustrated in Fig. 1. Upon exposure to organic solvents such as tetrahydrofuran (THF), the NFMs, loaded with the hydrophobic Nile Red (NR) dye molecules, are readily dissolved resulting in a burst-release of the cargo tethered to the surface into the solvent.

Naphthol-functionalised micelles were designed consisting of a diblock amphiphilic copolymer 2, which was synthesised in a stepwise manner by reversible addition-fragmentation chain transfer (RAFT) polymerisation as depicted in Fig. 2. The first

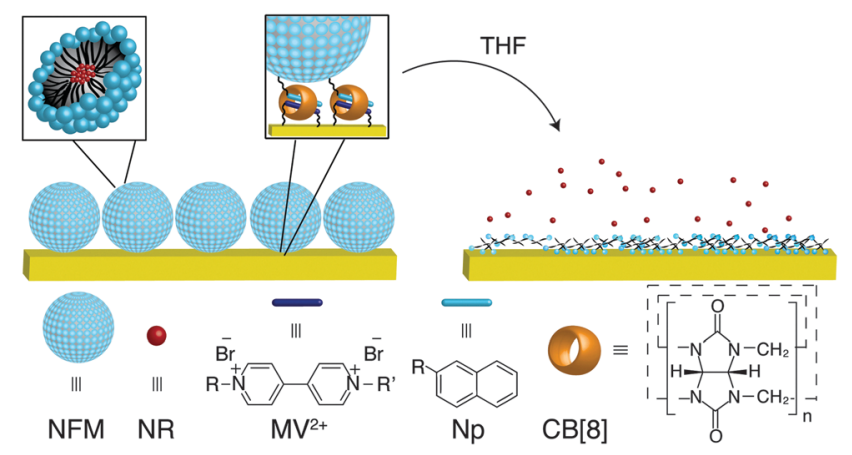

Fig. 1 Schematic illustration of the surface immobilisation of NFMs via CB[8]rotaxanes and the solvent-induced burst release of loaded guest molecules. 


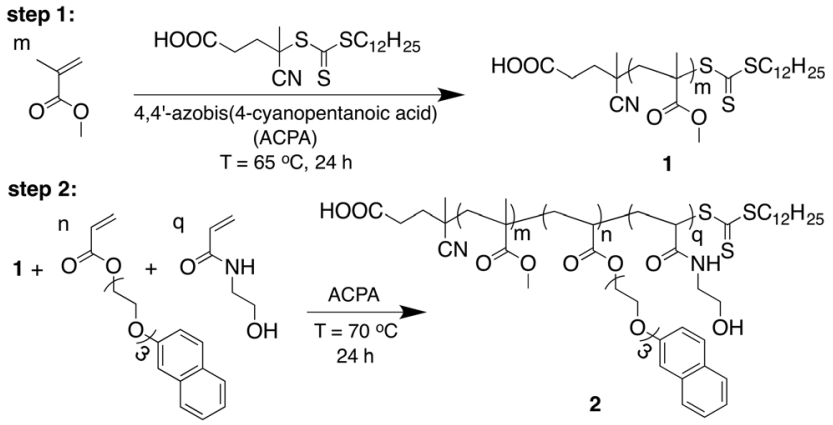

Fig. 2 Synthetic scheme for the two-step preparation of Np-functionalised amphiphilic diblock copolymer 2 by RAFT polymerisation.

block contained poly(methyl methacrylate) (poly(MMA)) 1 and was synthesised in 2-butanone using standard RAFT polymerisation conditions. Gel permeation chromatography (GPC) analysis in THF resulted in a molecular weight of $11 \mathrm{kDa}\left(M_{\mathrm{n}}\right)$ for block 1 . The polymer chain was then extended with a second block, which contained $N$-hydroxyethyl acrylamide (HEAA) and 2-(2-(2-(naphthalen-2-yloxy)ethoxy)ethoxy)ethyl acrylate (NpA) to obtain the diblock copolymer 2 . GPC analysis in THF confirmed an increase in $M_{\mathrm{n}}$ to $19 \mathrm{kDa}$ after chain extension. ${ }^{1} \mathrm{H}$ NMR analysis (Fig. S2, ESI $\dagger$ ) showed the ratio between Np and MMA moieties was 0.06:1 in diblock copolymer 2 .

Micelles were formed via self-assembly in aqueous media, whereby linear amphiphilic diblock copolymer 2 directed the hydrophilic poly(HEAA-co-NpA) head to stretch into water and shield the hydrophobic poly(MMA) tail in the core. SEM of the sample, shown in Fig. 3A, confirmed the successful formation of uniformly-sized spherical micelles. An average hydrodynamic diameter $\left(D_{\mathrm{h}}\right)$ of $375 \mathrm{~nm}$ was recorded by dynamic light scattering (DLS) analysis, with a polydispersity (PD) of 0.065 (Fig. 3B).

The $\mathrm{CB}[8]$-rotaxane functionalised Au surface can readily capture NFMs through host-guest recognition of the Np moieties on the hydrophilic heads of the NFMs. After simple dipping of the $\mathrm{CB}[8]$ rotaxane functionalised substrate into an aqueous solution of NFMs $([\mathrm{Np}]=0.5 \mathrm{mM})$ for $30 \mathrm{~s}$, the NFMs were successfully immobilised onto the Au substrate. As shown by the AFM image in Fig. S3A ( $\mathrm{ESI} \dagger$ ), the surface-bound NFMs exhibited a spherical morphology, consistent with SEM imaging prior to surface immobilisation (Fig. 3A). The NFMs appeared to be densely packed on the Au surface. In the $1 \mu \mathrm{m}$ $\times 1 \mu \mathrm{m}$ scanned area in Fig. S3A (ESI $\dagger$ ), there are 53 micelles attached to the surface. Since the NFMs displayed a monolayer conformation on the functional surface, they are likely immobilised
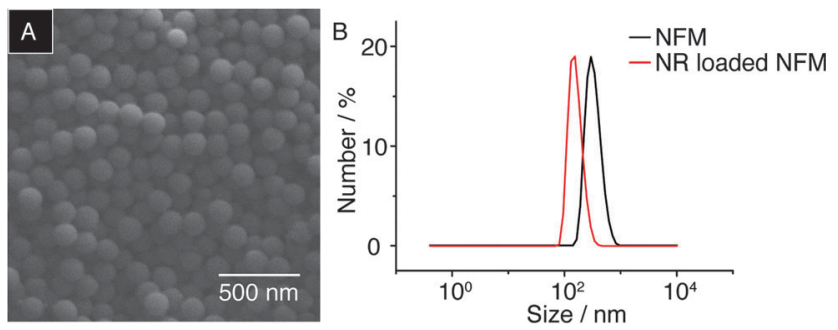

Fig. 3 (A) SEM image of NFMs cast onto a glass slide. (B) Hydrodynamic size distribution of NFMs measured by DLS. through specific $\mathrm{CB}[8]$-mediated host-guest interactions, rather than by random physisorption (see ESI $\dagger$ ).

The micellar morphology can only be maintained in water because the driving force for forming such structures arises from the solubility differences between the hydrophilic head and hydrophobic tail. When brought into contact with organic solvents the micellar nanostructure breaks down, resulting in the release of any loaded cargo. Therefore, changes in morphological structure of the NFMs upon exposure to THF was investigated by AFM imaging, as shown in Fig. S3B (ESI $\dagger$ ). After dipping the substrate with surfacebound NFMs into THF for $1 \mathrm{~s}$, the micellar structure started to break down and form flower-like collapsed domains as shown in Fig. S3B (ESI $\dagger$ ). Extending the dipping time to $1 \mathrm{~min}$ in THF resulted in the complete destruction of micellar structure. As shown in Fig. S3C $(\mathrm{ESI} \dagger)$, the roundish features completely disappeared from the substrate, leaving a relatively flat surface behind. AFM force curves between a bare Si tip and the resulting flat surface showed a monotonically increasing repulsive force during the approach, indicating the surface was covered with polymers (Fig. S4, ESI $\dagger$ ), likely copolymer 2 remaining from the broken NFMs.

In order to investigate the solvent-induced release behaviour of NFMs, Nile Red was added as a cargo during the formation of micelles in water. On account of its hydrophobic nature, NR was encapsulated within the micellar core and displayed a hydrodynamic diameter of $255 \mathrm{~nm}$, with a PD of 0.038 (Fig. 3B). Microcontact printing $(\mu \mathrm{CP})$ followed by supramolecular selfassembly on was then employed to immobilise the NR-loaded micelles onto functionalised Au surfaces through the formation of heteroternary complexes $\left(\mathrm{MV}^{2+} \cdot \mathrm{Np}\right) \subset \mathrm{CB}[8]$.

As shown in Fig. 4A, the vertical red lines of the pattern were deposited onto the surface by $\mu \mathrm{CP}$ with 2 -aminoethanethiol hydrochloride and the bare areas were back-filled with dodecanethiol for protection. $\mathrm{CB}[8]$-rotaxanes were subsequently prepared by an aldehyde coupling reaction with the amino groups on the surface as previously reported. ${ }^{30}$ This substrate with linear patterned $\mathrm{CB}[8]$ rotaxanes was then immersed into an aqueous solution of NRloaded NFMs $([\mathrm{Np}]=0.5 \mathrm{mM})$ for $30 \mathrm{~s}$. As shown in Fig. $4 \mathrm{~A}$, the red fluorescence from the NR dye was only found on the vertical lines where $\mathrm{CB}[8]$-rotaxanes are present, suggesting that the attachment of NFMs to the surface was indeed accomplished through the selective recognition of Np moieties by the surface-bound $\mathrm{CB}[8]$-rotaxanes.

The release of NR cargo from the surface-bound NFMs was visualised by the disappearance of the $\mu \mathrm{CP}$ pattern. After immersing
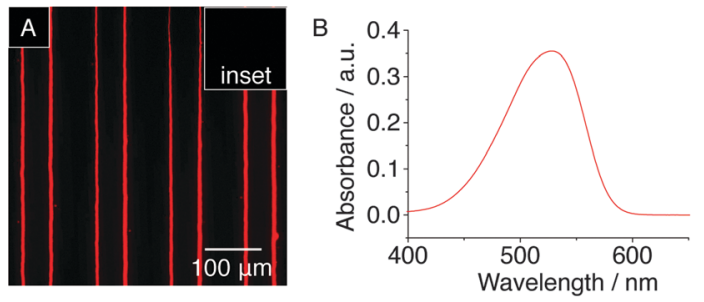

Fig. 4 (A) Fluorescence microscope image $\left(\lambda_{\mathrm{ex}}=557 \mathrm{~nm}\right)$ of $\mu \mathrm{CP}$ linear arrays of NR-loaded NFMs. The inset image is after exposure to THF for $1 \mathrm{~min}$. (B) UV/vis spectrum of NR released from the surface-immobilised NFMs by introducing THF for $1 \mathrm{~min}$. 


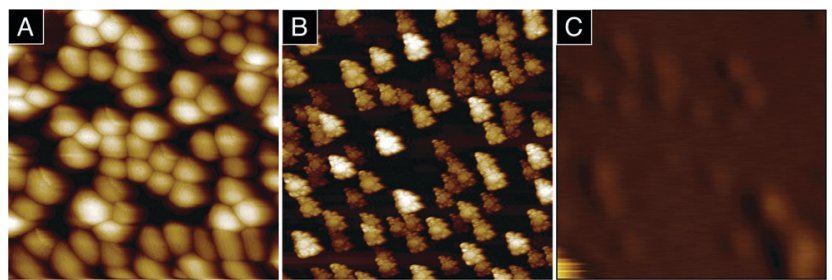

Fig. 5 AFM images of the solvent-induced burst release of NR from loaded NFMs $(1 \mu \mathrm{m} \times 1 \mu \mathrm{m})$ (A) before exposure to THF; (B) after $1 \mathrm{~s}$ immersion in THF; (C) after $1 \mathrm{~min}$ immersion in THF. All images were recorded in air in tapping mode.

the substrate in THF for $1 \mathrm{~min}$, the fluorescent pattern had completely disappeared, suggesting fast release of the NR cargo from the micelles (see inset Fig. 4A). The UV absorbance spectrum (Fig. 4B) of the THF solution displayed a peak at $525 \mathrm{~nm}$, which was consistent with the presence of NR and confirmed that the loaded NFMs were cable of a 'burst' release of their cargo to the solvent (see Fig. S6 in ESI $\dagger$ for detail explanation).

The morphological change of the loaded NFMs during the burst release of NR was followed by AFM imaging as shown in Fig. 5. In general, the change in conformation of the NR-loaded NFMs upon exposure to THF was similar to that of the unloaded NFMs (see Fig. S3 in ESI $\dagger$ ). The NR-loaded NFMs appeared as densely packed spherical objects on the $\mathrm{CB}[8]-$ rotaxane functionalised surface after immobilisation (Fig. 5A). Intermediate partiallycollapsed objects were captured (Fig. 5B) after $1 \mathrm{~s}$ soaking in THF, where the NR-loaded micelles exhibited a flower-like shape. After continuous immersion for $1 \mathrm{~min}$ in THF, all micellar features thoroughly disappeared resulting in a relatively flat surface. Several bumps could be observed on the surface (Fig. 5C); AFM force spectroscopy measurements confirmed these were polymers, as force curves displayed a gradually changing slope (Fig. S5, ESI $\dagger$ ). ${ }^{31}$ The change in morphology supported our hypothesis that the solubilisation of NFMs in THF caused a rapid breakdown in micellar structure with concomitant burst release of the loaded NR cargo. A similar burst release profile was observed with other organic solvents including chloroform and toluene, which also destroyed the surface-bound NFMs by solubilising their hydrophobic PMMA core, broadening the application of this system.

In conclusion, a supramolecular method to immobilise loaded soft-matter micelles onto functionalised Au surfaces followed by solvent-induced burst release of their cargo upon exposure to organic solvents was described. $\mathrm{CB}[8]$-rotaxane functionalised $\mathrm{Au}$ surfaces were utilised as a versatile platform to immobilise functionalised micelles via heteroternary complex formation, which displayed second-guest moieties around their periphery. The surface-bound micellar structures rapidly collapsed upon exposure to organic solvents, with dissolution of their hydrophobic polymeric core. Breakdown of the cargo-containing micellar objects provides an opportunity to controllably release encapsulated hydrophobic guest molecules in a 'burst'-like fashion upon external stimuli - in this case a change in solvent and polarity. This facile supramolecular approach enables the preparation of surface-bound nano-containers under mild conditions with high efficiency, which will likely prove useful in a number of biomedical applications including from surface patterning and cell interactions to sensing arrays. ${ }^{32}$

C. Hu thanks BP for supporting this work and Hughes Hall College Cambridge for a student scholarship. Y. Zheng was supported by an ERC starting investigator grant (ASPiRe 240629). Z. Yu is supported by an EPSRC grant (EP/H046593/1).

\section{References}

1 B.-H. Sohn, J.-M. Choi, S. I. Yoo, S.-H. Yun, W.-C. Zin, J. C. Jung, M. Kanehara, T. Hirata and T. Teranishi, J. Am. Chem. Soc., 2003, 125, 6368-6369.

2 Y. Lu, Y. Yang, A. Sellinger, M. Lu, J. Huang, H. Fan, R. Haddad, G. Lopez, A. R. Burns, D. Y. Sasaki, J. Shelnutt and C. J. Brinker, Nature, 2001, 410, 913-917.

3 A. Sellinger, P. M. Weiss, A. Nguyen, Y. Lu, R. A. Assink, W. Gong and C. J. Brinker, Nature, 1998, 394, 256-260.

4 Y. Kang and T. A. Taton, Angew. Chem., Int. Ed., 2005, 44, 409-412.

5 G. B. Webber, E. J. Wanless, V. Bütün, S. P. Armes and S. Biggs, Nano Lett., 2002, 2, 1307-1313.

6 T. Azzam and A. Eisenberg, Langmuir, 2007, 23, 2126-2132.

7 F. Ercole, T. P. Davis and R. A. Evans, Polym. Chem., 2010, 1, 37-54.

8 G. Webber, E. Wanless, S. Armes, Y. Tang, Y. Li and S. Biggs, J. Adv. Mater., 2004, 16, 1794-1798.

9 B.-S. Kim, R. C. Smith, Z. Poon and P. T. Hammond, Langmuir, 2009, 25, 14086-14092.

10 B.-S. Kim, S. W. Park and P. T. Hammond, ACS Nano, 2008, 2, 386-392.

11 E. R. Gillies, T. B. Jonsson and J. M. J. Fréchet, J. Am. Chem. Soc., 2004, 126, 11936-11943.

12 Q. Yan, J. Yuan, F. Zhang, X. Sui, X. Xie, Y. Yin, S. Wang and Y. Wei, Biomacromolecules, 2009, 10, 2033-2042.

13 Y. Bae, S. Fukushima, A. Harada and K. Kataoka, Angew. Chem., Int. Ed., 2003, 42, 4640-4643.

14 J. Rodríguez-Hernández and S. Lecommandoux, J. Am. Chem. Soc., 2005, 127, 2026-2027.

15 N. Rapoport, Prog. Polym. Sci., 2007, 32, 962-990.

16 C. M. Schilli, M. Zhang, E. Rizzardo, S. H. Thang, Y. K. Chong, K. Edwards, G. Karlsson and A. H. E. Müller, Macromolecules, 2004, $37,7861-7866$

17 A. P. Goodwin, J. L. Mynar, Y. Ma, G. R. Fleming and J. M. J. Fréchet, J. Am. Chem. Soc., 2005, 127, 9952-9953.

18 H.-i. Lee, W. Wu, J. Oh, L. Mueller, G. Sherwood, L. Peteanu, T. Kowalewski and K. Matyjaszewski, Angew. Chem., Int. Ed., 2007, 46, 2453-2457.

19 N. Benkirane-Jessel, P. Schwinté, P. Falvey, R. Darcy, Y. Haïkel, P. Schaaf, J.-C. Voegel and J. Ogier, Adv. Funct. Mater., 2004, 14, 174-182.

20 F. Tian, D. Jiao, F. Biedermann and O. A. Scherman, Nat. Commun., 2012, 3, 1207.

21 T. Huang, F. Meng and L. Qi, J. Phys. Chem. C, 2009, 113, 13636-13642.

22 L. Strimbu, J. Liu and A. E. Kaifer, Langmuir, 2003, 19, 483-485.

23 I. Willner, V. Pardo-Yissar, E. Katz and K. T. Ranjit, J. Electroanal. Chem., 2001, 497, 172-177.

24 A. Harada, Acc. Chem. Res., 2001, 34, 456-464.

25 H. Shigekawa, K. Miyake, J. Sumaoka, A. Harada and M. Komiyama, J. Am. Chem. Soc., 2000, 122, 5411-5412.

26 J. W. Lee, S. Samal, N. Selvapalam, H.-J. Kim and K. Kim, Acc. Chem. Res., 2003, 36, 621-630.

27 J. Kim, I.-S. Jung, S.-Y. Kim, E. Lee, J.-K. Kang, S. Sakamoto, K. Yamaguchiand and K. Kim, J. Am. Chem. Soc., 2000, 122, 540-541.

28 J. Lagona, P. Mukhopadhyay, S. Chakrabarti and L. Isaacs, Angew. Chem., Int. Ed., 2005, 44, 4844-4870.

29 F. Biedermann, M. Vendruscolo, O. A. Scherman, A. De Simone and W. M. Nau, J. Am. Chem. Soc., 2013, 135, 14879-14888.

30 C. Hu, Y. Lan, F. Tian, K. R. West and O. A. Scherman, Langmuir, 2014, 30, 10926-10932.

31 H. J. Taunton, C. Toprakcioglu, L. J. Fetters and J. Klein, Nature, 1988, 332, 712-714.

32 A. Blanazs, S. P. Armes and A. J. Ryan, Macromol. Rapid Commun., 2009, 30, 267-277. 